\title{
Scurvy and Flu in 1900: The Truth Lost in Evidence
}

\author{
Tereza Kopecka \\ Charles University, Institute for History of Medicine and Foreign Languages Prague, Czech Republic \\ tera.houbicka@gmail.com
}

\begin{abstract}
In the last third of the 19th century, the germ theory of infection had been reliably proved and widely accepted, new principles of microbiological research were laid down and many infectious diseases explained. But medicine was not ready yet to explain all the illnesses. Despite the thorough work of many scientists, substantial facts were still unknown - e.g. existence of most viruses, autoimmunity processes or micronutrients. The effort to explain all the diseases with existent knowledge gave rise to half-true concepts and mistakes. This paper deals with two interesting mistakes, found in the textbook of pathological anatomy and medical microbiology by Hlava and Obrzut, published in 1900-1901 in Austria-Hungary: the concept of scurvy as an infection caused by Bacillus scorbuti, and the causative role of the so-called „Pfeiffer's bacillus“ Bacillus influenzae, presently Haemophilus infuenzae, in the flu. These were not only theories but expert opinions based on the results of scientific research. Unfortunately, the methods were imperfect and performed/interpreted properly either, so they didn't allow the scientists to realize the erroneousness of their conclusions. The real causes of the diseases mentioned above were proven much later.
\end{abstract}

KEYWORDS: history, medicine, microbiology, scurvy, flu

\section{Introduction}

The year 1900 was not only the beginning of an era of revolutionary changes. The century that had just ended, yet comprised an essential turnover of western civilization. Europe was repeatedly destroyed by wars that determined its organization for a long time. The population however increased twofold and its mentality changed fundamentally.

It shifted from absolutism to democracy, to the process of formation of national identities and to autonomy inside the centuries-old monarchies. Major progress took place in the gender issue (Lenderova 2016). Secularization became evident in all the fields of public life, mainly in education. The switch to secular education was associated with a change of goals of the students and thus their field preferences, forming of new specialties and an increase of educational requirements (Charle 2004).

An enormous advance of science came in the second half of the $19^{\text {th }}$ century. Charles Darwin disproved the doctrine of creation by the work On the origin of species (Darwin 1859), which was one of the most dramatic moments of the $19^{\text {th }}$ century, followed by tens of years of stormy discussions (Komarek 2002). Rudolf Virchow refuted the theory of abiogenesis and laid the foundations of modern biology (Virchow 1858) which persist up to now. The only exception was the era of comrade Lepeshinskaya (1954), who attempted to substitute science by pseudoscience in the 1950s.

After centuries of humoralism, miasmas, iatrochemistry, iatrophysics, and other theoretical schools, scientific i.e. evidence-based medicine came to dominate. Works of Louis Pasteur, Edwin Klebs, Robert Koch, Joseph Lister, and many others gave birth to microbiology and the modern concept of infection (Temkin 1953). An essential question was formulated soon after that: Which illnesses are actually infectious? A precise answer has not been given to date.

The effort to answer the questions was enormous, but there were many methodological problems to overcome - e.g. the principle of causality, as the case of anthrax shows. The first proved infectious agent Bacillus anthracis was discovered by Casimir Davaine (Davaine 1863), who described it, but was not able to prove its causal relationship with anthrax. He observed the illness even in animals, which were given a solution removed from bacteria. Robert Koch sorted this problem out in 1876 by the discovery of spores and methodically consistent revision of Davaine's work, which provided conclusive evidence of its correctness (Carter 1985).

Diseases with epidemic occurrence were the first candidates for research of possible infectious etiology. It was confirmed in some of them, whereas disproved in others. Nevertheless, in the beginning, the results were often ambiguous. 


\section{Methods}

This paper is based on an analysis of the content of the textbook of pathological anatomy and medical microbiology „Vseobecna a specialni pathologicka anatomie“, written by respectable pathologists Jaroslav Hlava and Ondrej Obrzut and published in Prague (Austria-Hungary) in 1900-1901 (Hlava\& Obrzut 19001901). It has been digitized by the National Medical Library and is openly available at the website kramerius.medvik.cz.

This publication meets the criteria of the then scientific standards, however, contains several interesting mistakes. These mistakes are not of dogmatic nature: they are expert opinions based on scientific research.

\section{Scurvy epidemics}

The concept of scurvy as an infection is one of the most interesting mistakes in the history of medicine. Yet we can find it in this book, on pages 131 and 132,

"Scorbut (Scurvy). This term is used for an illness that occurs sometimes endemically (in prisons) or epidemically (on marine ships), characteristic by hemorrhagic to ulcerative gingivitis, intermuscular hemorrhage and internal hemorrhage of the abdominal organs, which result in anemia. Some authors consider scurvy as an illness from poor nutrition (lack of vegetables and fresh meat) and other hygienic deficiencies, whilst others perceive it as an infectious disease, arising from the gingiva and spreading to the whole body. Babes discovered thin bacilli - which caused a hemorrhagic process in dogs - Bacillus scorbuti, not only in hemorrhagic gingivitis, but also in blood and internal organs, and he assumes this species probably causes scurvy. It is natural that other microbes are also found in bloodstream and organs (streptococci, staphylococci) because secondary sepsis can arise from gingivitis by settling of pathogenic bacteria. But the findings of Babes still need confirmation."

This text shows that pathologists of the $19^{\text {th }}$ century knew scurvy very well, but they were not sure about its cause. The cited article about infectious cause of scurvy is probably „Ueber einen die Gingivitis und Hemorrhagien verursachenden Bacillus bei Skorbut.“, published in Deutsche Medicinische Wochenschrift in 1893 (Babes 1893). There he described his experience with diagnostics and treatment of scurvy. He analyzed tissues of ill persons, made attempts to induce experimental scurvy in animals, and also proposed the principle of development of scurvy.

He interpreted bleeding found in animals who were injected suspension of putrid tissues and infectious liquids, as a proof of successful induction of scurvy. As he concludes, the symptoms of scurvy are a consequence of the actions of toxins (probably exotoxins).

But although the article is quite extensive (11 pages), Babes didn't really provide conclusive evidence that he isolated and identified a microbe, which has an important role in the pathogenesis of scurvy. He described its microscopic features in an uncertain way, isolation process remains unclear, passaging on animals produced a different culture and the situation gives a chaotic impression.

One of the interesting aspects of this paper is the absence of respect to Koch's postulates. But was it a mistake?

\section{A. The Pioneers of Microbiology}

Professor Victor Babes was a respected Romanian microbiologist, a member of the generation of scientists who set up the principles of medical microbiology, struggling with an enormous volume of unclear and uncertain findings. And the development of other modern branches of science (e.g. pathologic physiology) which could have helped to resolve the problems, was also in its infancy.

Despite the pioneering era, this paper suffers from several significant imperfections. When describing the bacteria, Babes did not mention the source of bacteria (tissue or culture), which makes any interpretation impossible. Animal experiments are described in a superficial way, so they could not be repeated. The description of aerobic cultivation is confusing, whereas anaerobic cultivation (if it was performed) is not described at all.

Babes complained of difficulties in cultivation, mainly numerous colonies of Streptococci, which impede the growth of other microbes. He did not name other species, which is natural - the 
microbiome of the oral cavity was then neither identified nor taxonomically organized. E.g. members of the Neisseria species have been (except the primary pathogens $N$. gonorrhoeae and $N$. meningitidis) discovered in the $2^{\text {nd }}$ half of the $20^{\text {th }}$ century (Knapp 1988).

Moreover, the microscopic appearance of Bacillus scorbuti suggests that Babes probably worked with a mixed culture.

"Bacilli obtained from gums and tissues of rabbits are oblong, curved, sharpened at the ends, sized approximately $0,3 \mu \mathrm{m}$ in width and $3 \mu \mathrm{m}$ in length, but twice longer rods and wavy fibers can be also found. They are somewhat thinner and significantly longer than cholera bacilli and show a remarkable dissimilarity in length and width. The youngest individuals look like diplobacteria." (Babes 1893)

The cited finding practically fits the description of normal mixed culture obtained from an oral swab. It remains unclear what Babes really observed, but modern medical microbiology, despite the frequent use of the term "pleomorphic bacteria", would not mention the existence of a species with morphology varying between diplococci, curved rods, and fibers of non-uniform width.

A contemporary microbiologist would probably ask about Gram-staining appearance because the different color would warn Babes about probable heterogeneity of the culture. The paper states that they were Gram-negative, but we cannot rely on that. Results of Gram staining vary significantly after the applied method, and besides, the bacteria were cultivated in a non-standard way that could have changed their appearance significantly.

The key to the failure of this paper might be the criteria of positivity of the experiments, which were too loose. Symptoms assessed as experimentally induced scurvy were actually nonspecific changes associated with severe systemic infection and/or reaction to alien tissue. Internal bleeding occurs frequently during septic shock due to thrombocytopenia (Bedet et al. 2018).

Even the bacteria, cultivated from the bloodstream and tissues of the animals, would not necessarily stem from the inoculate. They might represent contamination or secondary infection.

\section{B. A Chance for Success?}

Immaturity of the methods was the essential negative factor. Cultivation media used in this research (broth, agar, gelatine, glycerine agar, and sugar agar) were up-to-date but actually poor and barely helpful for proper cultivation.

Furthermore, as the text shows, Babes probably performed only aerobic cultivation and his methods of inoculation to media will probably remain a mystery. Superficial inoculation on solid cultivation media (which is now standard) was not matter-of-course. E.g. Robert Koch preferred mixing the inoculate with warm gelatine (Buxton 2005).

But an assumption of clear and uniform rules dominating the emerging microbiology would be completely wrong. Due to lack of evidence and general "youth" of the science, every scientist created his methods himself. This can be illustrated by the huge differences of cultivation of some bacteria, as we will see in the case of Haemophilus influenzae. Some scientists cultivated it successfully in the 1890s, others failed even in the 1910s (Svestka 1918).

But these "first steps" had to be done and their authors should not be criticized. Knowledge and experience that new microbiologist gains during a few months now were beyond the borders of fantasy the $19^{\text {th }}$ century. Bacteriology served only for research and examination of serious cases. Neither methods allowing successful cultivation and identification of hundreds of species, nor routine diagnostic facilities then existed. Medical microbiology was practiced in institutes of pathology and only in the 1950s separate institutes of medical microbiology were commonly established (Wagner 2003, 81).

Assessment of the oral flora in such conditions must have been very difficult. It is highly varied and physicians spent tens of years searching for the key to its interpretation. In some points, they are still not of one mind. Expert opinions about pathogenic potential of various bacteria differ mostly, but the reason is not lack of data: pressure on rational indication of antibiotic treatment is the rub today (Cordoba \& Llor 2019). 


\section{Why Respect Koch's Postulates?}

Koch's postulates were a mainstay in the development of medical microbiology and infectology. They offered a simple tool to determine causality of infectious diseases. But even Koch himself knew that they were not completely correct. They didn't take into account cases of asymptomatic carrying, the immunological reaction of the organism, microbes that are difficult to cultivate, and other aspects. Despite the benefit for bacteriology, they delayed the development of virology by tens of years (Antonelli \& Cutler 2016).

Koch formulated them first in 1882 when he discovered the cause of tuberculosis Mycobacterium tuberculosis. He was invited to a gathering of the Berlin Physiological Society to present his findings. To persuade the audience about the causal relationship between Mycobacterium tuberculosis and tuberculosis, he declared the first version of four postulates. By a quirk of fate, this bacterium does not conform to them (Susser \& Stein 2009, 112). We can cite the postulates in a later version: (Antonelli \& Cutler 2016).

1. An alien structure must be exhibited in all cases.

2. The structure must be shown to be a living organism and must be distinguishable from all other micro-organisms.

3. The distribution of micro-organisms must correlate with and explain the disease phenomena.

4. The micro-organism must be cultivated outside the diseased animal and isolated from all disease products which could be causally significant.

5. The pure isolated micro-organism must be inoculated into test animals and these animals must then display the same symptoms as the original diseased animal.

Koch himself considered most important part of his postulates the requirement of obtaining a pure culture from the infectious focus and development of the illness after inoculation of the culture to animals (of the same species, if possible) (Carter 1985).

This wording shed an unpleasant light on Babes's paper, but without justification. Koch came down from the demanding version of postulates in 1890 . The new version was formulated at the $10^{\text {th }}$ International Medical Congress in Berlin as follows:

"However, if it can be proved: first that the parasite occurs in every case of the disease in question, and under circumstances which can account for the pathological changes and clinical course of the disease; secondly, that it occurs in no other disease as a fortuitous and nonpathogenic parasite; and thirdly, that it, after being fully isolated from the body and repeatedly grown in pure culture, can induce the disease anew; then the occurrence of the parasite in the disease can no longer be accidental, but in this case no other relation between it and the disease except that the parasite is the cause of the disease can be considered." (Rivers, 1937; Susser \& Stein, 2009)

\section{The History of Scurvy}

Today we are sure that scurvy is a vitamin $\mathrm{C}$ (ascorbic acid) deficiency. But the concept of nutritional deficiency emerged relatively late - for night-blindness in the $17^{\text {th }}$ century and for other diseases since the $19^{\text {th }}$ century (McDowell 2013).

The origin of scurvy was probably associated with agriculture, that enabled the human race to migrate to regions that would not provide enough food year-round. Dried grains of cereals can be stored for a long time, which taught people how to overcome long winters in the moderate zone. But they also caused the problems with vitamin $C$, because they contain only very little amounts of this substance.

Just like many other diseases, scurvy had been discovered and forgotten repeatedly. Ancient Egyptians knew - The Ebers Papyrus (1500 BC) mentions the disease and its treatment by onion (Mayberry 2004). Greek physicians knew scurvy, but they were not able to treat it, and medieval Europe inherited this attitude. Written evidence of scurvy can be found only since the $13^{\text {th }}$ century, firstly in connection with the $7^{\text {th }}$ Crusade (Mayberry 2004).

During this Crusade, French troops arrived in Egypt, where they got stuck in the delta of Nile. The soldiers had an unbalanced diet, eating practically only eels, fished out from the Nile. But those 
eels lived mainly on the dead bodies of the soldiers that were still flowing on the river (Clemetson 2018 , 9). The soldiers contracted an illness, which is today considered as scurvy. Bishops and cardinals blamed "sinful life", but Jean de Joinville, a secular author, found a possible natural cause: an infection spread by eels (Mitchell 2004, 186). That means the concept of infectious scurvy was not new in the $19^{\text {th }}$ century.

The golden age of scurvy was associated with the expansion of seafaring. Vasco da Gama, Ferdinand Magellan, and many others encountered this disease, which became the leading cause of death on the sea between 1500 and 1800 .

Various experts announced that scurvy can be prevented by a diet rich of fresh meat, fruits, and herbs. But this knowledge had not been implemented into practice for a long time. James Lind published his revolutionary work about scurvy in 1753 and despite the fact that there was practically nothing new, it was the key to the acceptation of the nutritional theory of scurvy (Anon 2019).

But it was not only the sea, where scurvy used to kill. Many casualties of the American Civil War were not killed on the battlefields, but died from an illness, including scurvy. The general public was informed by leaflets how to support their soldiers, e.g. young women were asked to send onions to their loved ones instead of love letters (Mayberry 2004).

The discovery of the cause of the illness beri-beri (1897 Christiaan Eijkman) and the development of modern chemistry led to the opening of a new branch of medicine, which is dedicated to nutrients. Nutritional deficiencies were the real causes of many diseases of "epidemic occurrence" and they still are. They occur due to poverty and newly due to westernization and alcoholism (Schweich, De Voeght, Sacré, Bernard, \& Michels 2018).

In 1928, when Albert Szent-György discovered vitamin C, the discussions about scurvy ended once forever. But in the early 1920s, we can still meet the interpretation of scurvy as an infectious disease (Pesic 1920, 1921).

\section{The Flu and Haemophilus influenzae}

It is worth heading back to the textbook and read the chapter dealing with the flu. On pages 126 and 127 we find this:

„Influenza (Flu.) Bacillus influenzae, discovered by Pfeiffer, is the smallest known bacillus, which can be seen in couples or clusters, its sporulation is not known and in Gram staining is negative; grows only on agar plates spread with blood in body temperature; it is pathogenic only for primates; causes the flu with high probability. Influenza is an epidemic disease characteristic by catarrhal inflammation of the nasopharyngeal mucosa and trachea, descending in soma cases to the bronchi or even lungs, where dense lobular or lobar croupous pneumonia arises. Thus the flu is a local process, which causes toxemia; in other cases, a systemic bacteriemia occurs, as Bacilli influenzae have been discovered in bloodstream, spleen, and meninx in cases of hemorrhagic encephalitis and ulcerative endocarditis. Sometimes infection by B. influenzae comes together with streptococci or pneumococci, local or systemic."

The history of interpretation of Haemophilus influenzae (HAIN, formerly named Bacillus influenzae or Bacillus Pfeifferi) as a causal agent of the flu is closely related to Richard Pfeiffer. He discovered this bacterium in 1892 and went defending it for tens of years, but in the end, he finally had to retreat.

\section{E. History}

The flu is one of the diseases that we can trace back to the antiquity. In the $19^{\text {th }}$ century, it underwent substantial changes, mainly in Europe. The increase of population that occurred chiefly in cities, facilitated its spread by personal contact. Another important factor was the boom of railways that connected distant parts of Europe, enabled sick persons to travel fast and thus contributed to the quick spread of the flu on a global scale (Kempinska-Miroslawska \& Wozniak-Kosek 2013).

The pandemic known as the Russian flu occurred in Europe in 1889 - 1892 (1894). From the contemporary point of view, it doesn't seem to be serious - we have witnessed pandemics of the Swine flu and SARS, we know several past pandemics, e.g. the Spanish flu that devastated the world 
during the World War I and a long time after its ending. These New Age plagues can make us think that the Russian flu was just a mild cold, but it was not.

And in this very time, the German physician Richard Pfeiffer made one of the successes of his life: the discovery of the influenza agent.

He published his findings first as a short text (some kind of preliminary notice) named „Vorläufige Mittheilungen über die Erreger der Influenza“ in the journal Deutsche Medicinische Wochenschrift in 1892 (Pfeiffer 1892). The complete paper was published as „Die Aetiologie der Influenza“ in the journal Zeitschrift für Hygiene und Infektionskrankheiten in 1893 (Pfeiffer 1893). He showed a high standard of expert and academic work, citing his colleagues and describing quite exactly all the methods and results. His findings seem really convincing and it is no wonder that they were accepted smoothly (Van Epps 2006).

\section{F. Difficult Cultivation}

Pfeiffer, as well as Babes, had to overcome problems with the cultivation of his microbe, as the text of 1892 shows. Haemophilus grew on his cultivation media in tiny colonies and Pfeiffer had to use a magnifying glass to see them. His cultures always lost viability quickly - not surprisingly, as this species is really demanding and delicate.

In the cited textbook the cultivation is described as successful only on agar spread with blood. Haemophilus influenzae really needs two "growth factors" - factor X (hemin) and factor V (NAD" nicotine adenine diamide). These substances are present in erythrocytes, but HAIN has no hemolysin to break them. That is the cause of the phenomenon named satellitism - growth around the colonies of Staphylococcus aureus, which is a potent source of various types of hemolysins and thus creates a suitable environment for HAIN. But Grassberger described this phenomenon only a few years after Pfeiffer's discovery (Norskov-Lauritsen 2014).

Pfeiffer did not mention blood in his 1892 article, only sugar agar. But the blood must have been present, otherwise, HAIN would not grow. The 1893 paper determines clearly the close relationship of this bacterium to blood (Salfellner 2017, 16). Its pleasure in blood was later the reason for its actual name.

A modern microbiologist would probably ask how come HAIN grew on blood without the presence of Staphylococci. The key to success could have been proper smearing of blood on the surface of agar that disrupted the membranes of the erythrocytes.

\section{G. Toxic Fashion}

The last decade of the $19^{\text {th }}$ century attributed many diseases to the toxic activity of microbes, which was evident also in the previous topic. Thus arose one of the mistakes, mentioned in the textbook. The flu is described as a local process with systemic symptoms caused by toxemia and occasionally bacteriemia. But it actually is a systemic viral disease with various organ manifestation.

The symptoms are caused by the direct action of the virus, but also by immune reaction of the host organism and by bacterial superinfection that occurs regularly. The participation of bacterial superinfection in the symptoms is so significant that formerly it was considered as mandatory synergy (Rivers 1937).

The "fashion" of toxins is still actual, although we now possess many detailed data about them. In bacteria, we can divide them into exotoxins and endotoxins. Exotoxic action is not substantial in Haemophilus influenzae (Musher 1996), but endotoxic action is very important. And Richard Pfeiffer was one of the scientists who contributed to the discovery of endotoxins.

The cell wall of most Gram-negative bacteria contains lipopolysaccharide (LPS) - "classic endotoxin", one of the principal factors of pathogenicity. Haemophilus species (just as Neisseria, Bordetella, and Branhamella) contains another substance, named lipooligosaccharide. Its appearance and function are similar to LPS. It is a mediator of inflammation, protects the bacterium from external agents and provides adhesion to the host cell. (Musher, 1996; Preston, Mandrell, Gibson, \& Apicella 1996).

Despite the erroneous association between the flu and HAIN that Pfeiffer proposed, his view of pathogenicity of this bacterium was not just a blind attempt. The endotoxin theory is the very proof of 
the complexity of his approach. But the 1892 flu article does not mention endotoxins yet. According to (Rietschel \& Cavaillon 2003) he started working on this topic during the experiments with Vibrio cholerae. After all, his paper about Vibrio sp. is really the first one that formulates the endotoxin theory (Pfeiffer 1892).

\section{H. Mistake with Long-term Sequelae}

The name of Haemophilus influenzae is very confusing for medical students, but it is just a memorial of fallibility, which is true for each one of us. And this bacterium is a good candidate for this situation.

Today we are able to distinguish viral infection from bacterial, but in the $19^{\text {th }}$ century the viruses attacking respiratory system were not known yet and there were no reliable methods to distinguish between the flu, primary respiratory infection caused by Haemophilus infection and flu with a secondary infection with Haemophilus species.

Haemophilus sp. is a regular constituent of the microbiome of the upper respiratory tract, but some types and especially under certain conditions can be strongly pathogenic, not only in the upper respiratory tract: invasive infections such as pneumonia, meningitis or epiglottitis represent a significant cause of sepsis and an immediate life threat for the patient.

In the 1892 text, Pfeiffer states that in 31 patients with flu a pure massive culture of Haemophilus influenzae was obtained, whereas in a considerable number of controls with other diagnoses (bronchial catarrh, pneumonia or TB) it was absent. But the absence of Haemophilus influenzae in the specimens of bronchitis or pneumonia can be surely considered as a false negative result. Under the use of modern methods, HAIN is one of the most frequent isolates (Park et al. 2016). The same is valid in pneumonia (Park et al. 2016).

But the success of cultivation depends on the specimens and it is not easy to get a valid specimen from cases of pneumonia. A substantial part of sputum specimens is free from pathogenic bacteria (Cukic \& Hadzic 2016) and blood cultures had a primitive form with lower effectivity. Successful blood cultivation also depends on the physician's ability to assess the right moment of sampling, i.e. predict bacteriemia (Dreyer 2012). The $19^{\text {th }}$ century offered much worse conditions for these methods.

But it was not possible to avoid the fact that HAIN was gradually detected in unexpected specimens - liquids and swabs of patients suffering from different diseases (not the flu) and even in healthy people (Davis 1907).

\section{The Inevitable End of Bacillus influenzae}

One of the most important factors for a long life for this mistake was the difficulty of its cultivation. When the Russian flu pandemics ended, the topic was forgotten for some time but emerged once again with the Spanish flu. And the microbiological findings were not as uniform as described by Pfeiffer. HAIN was not even dominant in the specimens, there was a wide variety of other pathogens like pneumococci, staphylococci or Branhamella catarrhalis (Selter 1918). Pfeiffer's supporters believed that the absence of HAIN is a consequence of wrong cultivation methods, as they knew that it is not easy to gain a culture of this species. The debate escalated into a real battle that didn't finish even after the decline of the pandemic (Salfellner 2017, 16).

As long as it was possible to interpret negative results as false negative due to wrong methods, there was still a reason to defend HAIN and Pfeiffer really did, supported by many experts (Salfellner 2017, 16). But since the year 1924, when Oswald Avery discovered the unique cultivation medium named "chocolate agar", which is a reliable tool for the cultivation of HAIN, it became unavoidable to admit that in many specimens of patients suffering from the flu it is just not present (Barry 2005, 295).

The real cause of the flu, the Influenza Virus, was discovered in 1931 by Richard Shope. This success was possible only thanks to modern filters. They enabled scientists to prove that liquids, infected by the flu, remain infectious after the elimination of all the bacteria (Van Epps 2006).

\section{Conclusions: The Era of Mistakes}

This kind of mistakes was quite common in the pioneering era of medical microbiology. E.g. typhus fever was a complete mystery even in the 1910s, as we can verify in the Czech annotation of the paper by 
Markus Rabinowitch (Rabinowitsch 1911). Some famous scientists thought that the cause of typhus fever was a bacterium of the Micrococcus species (which is actually a harmless inhabitant of human and animal skin and mucous membranes). Others blamed protozoa, spirochetes, diplococci or rods. But there were also experts who admitted that they had never found any microbe in the victims (which was the only correct result with the then methods).

Later research showed that the causal agent of typhus fever Rickettsia prowazekii is a tiny bacterium demanding intracellular environment, the closest relative of mitochondriae (Andersson et al. 1998), which cannot be detected by classic bacteriological methods.

Henrique da Rocha Lima discovered this microbe in 1916, but it was not named after him. Many scientists sacrificed their own lives to this research and two of them (Howard Taylor Ricketts and Stanislaus von Prowazek) were awarded the taxonomic tribute (Bernardes Filho \& Avelleira 2015).

Mistakes, presented in this paper, were evidence-based bias. They emerged due to the immaturity of the methods, an incorrect application and/or interpretation of their results. Despite the overwhelming amount of data that provides modern science, mistakes still occur and they probably will always do. Precise work, the strict keeping of all the rules, humility and openness can be the key to avoid as many mistakes as possible.

\title{
Acknowledgments
}

Katerina Kripnerova for medical review and Petr Svobodny for historical review.

\author{
Abbreviations: \\ LPS = lipopolysaccharide \\ HAIN = Haemophilus influenzae \\ sp. $=$ species
}

\section{References}

Andersson, Siv G. E., Alireza Zomorodipour, Jan O. Andersson, Thomas Sicheritz-Pontén, U. Cecilia M. Alsmark, Raf M. Podowski, A. Kristina Näslund, Ann-Sofie Eriksson, Herbert H. Winkler, and Charles G. Kurland. 1998. 'The Genome Sequence of Rickettsia Prowazekii and the Origin of Mitochondria.' Nature 396(6707):133-40.

Anon. 2010. 'Lind J (1753)'. The James Lind Library. Retrieved 4 April 2019 (http://www.jameslindlibrary.org/lind-j1753/). Accessed on 2019/4/11.

Antonelli, G. and S. Cutler. 2016. 'Evolution of the Koch Postulates: Towards a 21st-Century Understanding of Microbial Infection.' Clinical Microbiology and Infection 22(7):583-84.

Babes, V. 1893. 'Ueber Einen Die Gingivitis Und Hämorrhagieen Verursachenden Bacillus Bei Skorbut.' DMW-Deutsche Medizinische Wochenschrift 19(43):1035-1037.

Barry, John M. 2005. The Great Influenza: The Epic Story of the Deadliest Plague in History. Penguin.

Bedet, Alexandre, Keyvan Razazi, Florence Boissier, Mathieu Surenaud, Sophie Hue, Stéphane Giraudier, Christian BrunBuisson, and Armand Mekontso Dessap. 2018. 'Mechanisms of Thrombocytopenia During Septic Shock: A Multiplex Cluster Analysis of Endogenous Sepsis Mediators.' Shock (Augusta, Ga.) 49(6):641-48.

Bernardes Filho, Fred and João Carlos Regazzi Avelleira. 2015. 'Henrique Da Rocha Lima.' Anais Brasileiros de Dermatologia 90(3):363-66.

Buxton, Rebecca. 2005. 'Blood Agar Plates and Hemolysis Protocols.' Retrieved $11 \quad$ April 2019 (http://www.asmscience.org/content/education/protocol/protocol.2885). Accessed on 2019/4/11.

Carter, K. C. 1985. 'Koch's Postulates in Relation to the Work of Jacob Henle and Edwin Klebs.' Medical History 29(4):353-74.

Charle, Christophe. 2004. Intelektuálové v Evropě 19. století. Historickosrovnávací esej s novým původním doslovem autora - Bibliografie dějin Českých zemí. Brno: CDK.

Cordoba, Gloria and Carl Llor. 2019. 'Overdiagnosis Paradigm: Not Suitable for Decreasing the Overuse of Antibiotics.' BMJ Evidence-Based Medicine.

Cukic, Vesna and Armin Hadzic. 2016. 'The Most Common Detected Bacteria in Sputum of Patients with Community Acquired Pneumonia (CAP) Treated In Hospital.' Medical Archives (Sarajevo, Bosnia and Herzegovina) 70(5):354-58.

Darwin, Charles. 1861. On the Origin of Species by Means of Natural Selection. New York: D. Appleton and Company.

Hlava, Jaroslav and Ondrej Obrzut. 1900-1901. Vseobecna a Specialni Pathologicka Anatomie. Prague: Bursik\&Kohout.

Kempińska-Mirosławska, Bogumiła and Agnieszka WoŸniak-Kosek. 2013. 'The Influenza Epidemic of 1889-90 in Selected European Cities - a Picture Based on the Reports of Two Poznań Daily Newspapers from the Second Half 
of the Nineteenth Century.' Medical Science Monitor: International Medical Journal of Experimental and Clinical Research 19:1131-41.

Knapp, J. S. 1988. 'Historical Perspectives and Identification of Neisseria and Related Species.' Clinical Microbiology Reviews 1(4):415-31.

Komarek, Stanislav. 2002. 'Anglická Biologie Doby Darwinovy.' In Dějiny kultury a civilizace Západu v 19. století Bibliografie dejin Ceskych zemi. Brno: CDK.

Lenderova, Milena. 2017. K Hrichu i k Modlitbe. Prague: Karolinum.

Lepeshinskaya, O. B. 1954. The Origin of Cells from Living Substance. Moscow: Foreign Languages Publishing House.

Mayberry, Jason. 2004. 'Scurvy and Vitamin C.' Retrieved $20 \quad$ March 2019 (https://dash.harvard.edu/bitstream/handle/1/8852139/Mayberry.html?sequence=2). Accessed on 2019/4/11.

McDowell, Lee. 2013. Vitamin History, the Early Years. Sarasota, FL: First Edition Design Pub.

Mitchell, Piers D. 2004. Medicine in the Crusades: Warfare, Wounds and the Medieval Surgeon. Cambridge University Press.

Musher, Daniel M. 1996. 'Haemophilus Species.' in Medical Microbiology, edited by S. Baron. Galveston (TX): University of Texas Medical Branch at Galveston.

Norskov-Lauritsen, Niels. 2014. 'Classification, Identification, and Clinical Significance of Haemophilus and Aggregatibacter Species with Host Specificity for Humans.' Clinical Microbiology Reviews 27(2):214-40.

Park, Ji Young, Sunghoon Park, Sun Hwa Lee, Myung Goo Lee, Yong Bum Park, Kil Chan Oh, Jae-Myung Lee, Do Il Kim, Ki-Hyun Seo, Kyeong-Cheol Shin, Kwang Ha Yoo, Yongchun Ko, Seung Hun Jang, Ki-Suck Jung, and Yong Il Hwang. 2016. 'Microorganisms Causing Community-Acquired Acute Bronchitis: The Role of Bacterial Infection'. PloS One 11(10):e0165553.

Pešič, Svetozar. 1920. 'O skorbutu kao infekcioznoj bolesti.' Liječnički Vijesnik (8-10).

Pešič, Svetozar. 1921. 'Du scorbut comme maladie infectieuse.’ Liječnički Vijesnik (2).

Pfeiffer, R. 1892. 'Untersuchungen über das Choleragift.' Zeitschrift für Hygiene und Infektionskrankheiten 11(1):393412.

Pfeiffer, R. 1892. 'Vorläufige Mittheilungen über die Erreger der Influenza.' DMW - Deutsche Medizinische Wochenschrift 18(2):28-28.

Pfeiffer, R. 1893. 'Die Aetiologie der Influenza.' Zeitschrift für Hygiene und Infektionskrankheiten 13(1):357-86.

Preston, A., R. E. Mandrell, B. W. Gibson, and M. A. Apicella. 1996. 'The Lipooligosaccharides of Pathogenic GramNegative Bacteria.' Critical Reviews in Microbiology 22(3):139-80.

Rietschel, Ernst Th. and Jean-Marc Cavaillon. 2003. 'Richard Pfeiffer and Alexandre Besredka: Creators of the Concept of Endotoxin and Anti-Endotoxin.' Microbes and Infection 5(15):1407-14.

Rivers, T. M. 1937. 'Viruses and Koch's Postulates.' Journal of Bacteriology 33(1):1-12.

Salfellner, Harald. 2017. Španělská chřipka: přiběh pandemie z roku 1918. Praha: Vitalis.

Schweich, M., De Voeght A., F. Sacré, V. Bernard, and V. Michels. 2018. '[Scorbut, historic disease ?]'. Revue Medicale De Liege 73(11):541-43.

Susser, Mervyn and Zena Stein. 2009. Eras in Epidemiology: The Evolution of Ideas. Oxford University Press.

Svestka, Vladislav. 1918. 'K Aetiologii Chripky z Roku 1918.' Casopis Lekaru Ceskych (34):620.

Temkin, Owsei. 1953. 'An Historical Analysis of the Concept of Infection.' In Studies in intellectual history, pp. $123-47$. Baltimore: Johns Hopkins Press.

Van Epps, Heather L. 2006. 'Influenza: Exposing the True Killer.' The Journal of Experimental Medicine 203(4):803.

Virchow, Rudolf. 1871. Die Cellularpathologie. Berlin: August Hirschwald.

Wagner, Vladimír. 2003. Symptomy Bezmoci. Prague: Galen. 